\title{
Magnetic resonance imaging of the siliceous skeleton of the demosponge Lubomirskia baicalensis
}

\author{
Werner E.G. Müller ${ }^{\text {a,* }}$, Oxana V. Kaluzhnaya ${ }^{\text {a,b }}$, Sergey I. Belikov ${ }^{\text {b }}$, Matthias Rothenberger ${ }^{\text {a }}$, \\ Heinz C. Schröder ${ }^{\mathrm{a}}$, Andreas Reiber ${ }^{\mathrm{c}}$, Jaap A. Kaandorp ${ }^{\mathrm{d}}$, Bertram Manz ${ }^{\mathrm{e}}$, \\ Daniel Mietchen ${ }^{\mathrm{e}}$, Frank Volke ${ }^{\mathrm{e}}$ \\ a Institut für Physiologische Chemie, Abteilung Angewandte Molekularbiologie, Universität, Duesbergweg 6, D-55099 Mainz, Germany \\ ${ }^{\mathrm{b}}$ Limnological Institute of the Siberian Branch of Russian Academy of Sciences, Ulan-Batorskaya 3, RUS-664033 Irkutsk, Russia \\ ${ }^{\mathrm{c}}$ Universidad de Los Andes Carrera $1^{a}$ No. 18 A-70, Bogota, Colombia \\ ${ }^{\mathrm{d}}$ Faculty of Mathematics, Computer Science, Physics and Astronomy, University of Amsterdam, Kruislaan 403, 1098 SJ Amsterdam, The Netherlands \\ ${ }^{\mathrm{e}}$ Fraunhofer Institut für Biomedizinische Technik, Arbeitsgruppe Magnetische Resonanz, Ensheimer Str. 48; D-66386 St. Ingbert/Saar, Germany
}

Received 5 June 2005; received in revised form 31 August 2005; accepted 20 September 2005

Available online 30 November 2005

\begin{abstract}
The skeletal elements (spicules) of the demosponge Lubomirskia baicalensis were analyzed; they are composed of amorphous, noncrystalline silica, and contain in a central axial canal the axial filament which consists of the enzyme silicatein. The axial filament, that orients the spicule in its longitudinal axis exists also in the center of the spines which decorate the spicule. During growth of the sponge, new serially arranged modules which are formed from longitudinally arranged spicule bundles are added at the tip of the branches. X-ray analysis revealed that these serial modules are separated from each other by septate zones (annuli). We describe that the longitudinal bundles of spicules of a new module originate from the apex of the earlier module from where they protrude. A cross section through the oscular/apical-basal axis shows that the bundle rays are organized in a concentric and radiate pattern. High resolution magnetic resonance microimaging studies showed that the silica spheres of the spicules in the cone region contain high amounts of 'mobile' water. We conclude that the radiate accretive growth pattern of sponges is initiated in the apical region (cones) by newly growing spicules which are characterized by high amounts of 'mobile' water; subsequently spicule bundles are formed laterally around the cones.
\end{abstract}

(c) 2005 Elsevier Inc. All rights reserved.

Keywords: Sponges; Lubomirskia baicalensis; Pattern formation; Siliceous skeleton; High resolution MRI; 3D-imaging

\section{Introduction}

Sponges [phylum Porifera] were the first animals to branch off from the common ancestor of all Metazoa, the Urmetazoa (Müller et al., 2004). The knowledge that some sponges comprise a siliceous skeleton, that is built from a framework of spicules, goes back to Grant (1826). After the discovery of the glass sponges (Schultze, 1860) and the finding that they also those comprise a siliceous spicular net-

\footnotetext{
* Corresponding author. Fax: +61313925243.

E-mail address: wmueller@uni-mainz.de (W.E.G. Müller).

$U R L:$ http://www.biotecmarin.de (W.E.G. Müller).
}

work, the Porifera were grouped into three classes: the phylogenetic oldest class of Hexactinellida, the Demospongiae and the youngest, the Calcarea (Kruse et al., 1998). The first two taxa contain spicules which are composed of polymerized silicic acid, while the latter produces calcium carbonate spicules.

The silica deposits in the siliceous spicules of Hexactinellida and Demospongiae are of hydrated, amorphous, and non-crystalline nature (see Hartman, 1981). The water content has been determined to be around 6-10\% (Arndt, 1930; Sandford, 2003), yielding an approximate formula of $\left(\mathrm{SiO}_{2}\right)_{2-5} \cdot \mathrm{H}_{2} \mathrm{O}$ (Simpson, 1984). In demosponges, the spicules can constitute up to $75 \%$ of the dry weight of the 
organism (Shimizu et al., 1998). In a thorough study on the silica deposition of desmas, complex formed spicules from a Lithistid demosponge, it could be demonstrated that in young spicules deposition starts with silica granules that have diameters between 100 and $160 \mathrm{~nm}$ (Pisera, 2003). In later stages, during maturation, the silica granular structures of the spicules are transformed to non-porous sheets which are arranged concentrically around the axial filament, as described by Pisera (2003). Therefore, it is very likely that the initial zone formed from the silicatein molecules of the axial filament produces granular particles, while the more peripheral silica layer(s) might be synthesized from silicatein molecules present in the extra-spicular space (Müller et al., 2005).

After demineralization of spicules a central axial filament is obtained which is composed of subunits of an enzyme termed silicatein (Cha et al., 1999). Silicatein belongs to the family of cathepsin L proteases (Cha et al., 1999 ) and is involved in the condensation/polymerization reaction of silica (Cha et al., 1999; Krasko et al., 2000). Recently, it could be demonstrated that spicule formation starts within specialized cells, the sclerocytes, around the axial filament. After the silica layer around the axial filament reaches a diameter of approximately $3-5 \mu \mathrm{m}$, thickness growth of spicules proceeds by apposition to the outside of the spicules (Müller et al., 2003, 2005). Also outside, around the spicules, a layer of silicatein exists which has been proposed to finalize their size and shape (Müller et al., 2003, 2005). In the extra-spicular space silicatein is organized, very likely, on collagen fibers (to be published).

At present the concentration of silicic acid in natural fresh- and seawater is low and reaches values of less than $3 \mu \mathrm{M}$ (Maldonado et al., 1999); the optimal silica concentration for the synthesis of the siliceous spicules has, however, been determined to be between 5 and $100 \mu \mathrm{M}$ (Jewell, 1935). From the fast growth rate of sponge spicules (for freshwater sponges $5 \mu \mathrm{m} / \mathrm{h}$; Weissenfels, 1989) it can be deduced that sponges must have an efficient system to obtain silica from the environment. A potential transporter which is very likely involved in silica uptake, has earlier been cloned and functionally characterized and was termed $\mathrm{Na}^{+} / \mathrm{HCO}_{3}{ }^{-}\left[\mathrm{Si}(\mathrm{OH})_{4}\right]$ cotransporter (Schröder et al., 2004b). Besides its role in the spicule formation, silicic acid was also found to cause a differential gene expression for, e.g., the morphogenetic protein noggin (Schröder et al., 2004a). Therefore, it was postulated that silicic acid is an environmental morphogenetic compound. In concert with the genetic repertoire, e.g., the homeodomain transcription factors and T-box proteins, silicic acid of seawater establishes the oscular/apical-basal axis in sponges (Müller, 2005).

In the approach to model morphogenesis of sponges, Kaandorp (1994) proposed that the growth process of these animals proceeds by deposition of new layers on top of the previous growth stage, a process which follows a radiate accretive architecture. Sponges have only an oscular/api- cal-basal axis (Müller, 2005); the oscule region can be considered as an organizer, since there organizer-specific genes are expressed, such as LIM-homeodomain, Brachyury, Frizzled receptor, noggin, and Iroquois. Especially in branching, arborescent sponges the oscular/apical-basal axis shows discrete identical, repetitive skeleton elements which we called serial modules (Müller, 2005). One module of a sponge with an anisotropic skeleton is composed of longitudinally arranged spicular bundles and is demarcated by tangential, interconnecting zones. The tangential zones or fibers correspond to the surfaces of the earlier growth stages.

Recently, the growth pattern of the Lake Baikal sponge Lubomirskia baicalensis has been described in more detail (Kaluzhnaya et al., 2005a). X-ray analyses of its skeleton revealed an architecture of a highly ordered arrangement of spicules. During longitudinal growth of the sponge branches new modules are added at the tip of the branches. Further biochemical and molecular biological studies showed that an oscular/apical-basal gradient of gene expression exists. While the steady-state expression level of silicatein is highest at the top of the branches, the highest level of the protein catabolizing enzyme is found at the basal region of the sponge. These data suggest that the serial modular growth of the branching sponges, here of $L$. baicalensis, follows a pattern where the proliferic zone of a sponge specimen is at the apical end of the branches. The spicules from $L$. baicalensis have been described in detail and were found to be organized in clusters, in bundles, within an organic matrix (Masuda et al., 1997).

In the present study, we investigated whether the serial modular growth pattern of the branched to arborescently growing $L$. baicalensis shows also on the level of spicule formation distinct zonations. Therefore the structural and ultrastructural pattern of spicule formation was analyzed. Together with the data on the growth/shape determining role of the organic axial filament in the spicules, a noninvasive technique, the advanced magnetic resonance imaging (MRI) technique, was applied. This approach had already been successfully applied to measure the mobility and distribution of water ('mobile' water) in fossils, composite materials, and biological material (e.g., Manz et al., 2004). Our results allowed the formulation of a model describing the accretive serial modular growth of the branches of L. baicalensis.

\section{Materials and methods}

\subsection{Sponge}

Specimens of the Baikalian sponge L. baicalensis (Pallas) were collected in September 2004 by SCUBA diving from depths of $8-15 \mathrm{~m}$ near the village Listvyanka. Skeletons of L. baicalensis were prepared by immersing the specimens into hypochlorous acid $(2.5 \%)$ at room temperature for 1 day. After washing, the skeleton was inspected. 


\subsection{Preparation of spicules and of the axial filaments}

Tissue samples were placed in hypochlorous acid (2.5\%); after stirring and sedimentation the spicules were collected. The dissolution of the siliceous "shell" of the spicules was achieved by addition of hydrofluoric acid ( $2 \mathrm{M} \mathrm{HF} / 8 \mathrm{M}$ $\mathrm{NH}_{4} \mathrm{~F}$ ), at $\mathrm{pH} 5$ and room temperature (Kaluzhnaya et al., 2005a), in the presence of Coomassie brilliant blue (R-250; $0.25 \%$ dissolved in $10 \%$ acetic acid $/ 45 \%$ ethanol). Photos were taken every minute through a light microscope to demonstrate the release of the pure axial filament from the spicules.

\subsection{Microscopy}

Scanning electron microscopy (SEM) analysis of spicules was performed with a Zeiss DSM 962 Digital Scanning Microscope (Zeiss, Aalen; Germany). The samples were mounted onto aluminum stubs (SEM-Stubs G031Z; Plano, Wetzlar; Germany) that had been covered with adhesive carbon (carbon adhesive Leit-Tabs G3347). Then, the samples were sputtered with a $20 \mathrm{~nm}$ thin layer of gold in argon plasma (Bal Tec Med 020 coating system; Bal Tec, Balzers, Liechtenstein). For the light microscopical studies an Olympus AHBT3 light microscope was used.

\subsection{Radiography}

The radiographs (X-ray analysis) were obtained on a full field digital mammography system (Lorad, Danbury, CT, USA). The images were taken with a tube voltage of $28 \mathrm{kV}$ at $8 \mathrm{mAs}$ and FFD $60 \mathrm{~cm}$.

\subsection{Nuclear magnetic resonance imaging}

The high resolution magnetic resonance (MR) microimaging studies of a sponge skeleton, which had been airdried for more than 7 days, were carried out in a Bruker Avance nuclear magnetic resonance (NMR) spectrometer operating at a proton Larmor frequency of $400 \mathrm{MHz}$. The spectrometer was equipped with standard microimaging probe and gradient amplifiers. The images were recorded using a standard three-dimensional spin-echo imaging sequence with a field of view of $15 \mathrm{~mm}, 128 \times 256 \times 256$ voxels $(z, x, y)$, giving a resolution of $59 \mu \mathrm{m}$ in $x$ and $y$ directions. Other parameters were: $T_{\mathrm{e}}=0.47 \mathrm{~ms}, T_{\mathrm{r}}=1 \mathrm{~s}$, and signal averages (Callaghan, 1991; Pampel and Volke, 2004).

\section{Results}

\subsection{Serial modules of the branches of L. baicalensis}

Lubomirskia baicalensis, that reaches sizes of up to $1 \mathrm{~m}$, exists as an encrusting form in depths between 3 and $7 \mathrm{~m}$, while at larger depths branches with rounded tips, which occasionally dichotomize, grow from the encrusting base (Fig. 1A). Already by eye inspection it becomes evident that the branches (diameter of $1-2 \mathrm{~cm}$ ) of such specimens are composed of $1-2.5 \mathrm{~cm}$ long septate modules, which are arranged along the growing axis of the branch. This growth pattern is underscored by X-ray analysis of the skeleton of the branches. Fig. 1B shows that within the branch the spicules are arranged in longitudinal bundles. At the septate zones (annuli) transversal lines demarcate the serial modules. A break of a branch occurs always in the middle of a serial module between two annuli; the surface of the upper piece protrudes as an almost circular cone into the socket formed by the surface of the lower module (Fig. 1C).

Fig. 2A depicts a scheme of the longitudinal section; it is outlined that the longitudinal bundles of spicules originate from the apex of the earlier module. From there, newly formed spicular bundles protrude. Slightly delayed, the tip of the branch changes from cone-shaped to cap-like, very likely by the outgrowth of spicule bundles from the lateral surface adjacent to the apex. In parallel the corresponding NMR images from the tip of the apex (top), the middle of a module and from an annulus (below) are given. This transition of the tips of the branches from cone-shaped to capped can frequently be seen in the natural environment (Fig. 2B); the cap-like tips (Fig. 2B (1-3)) broaden to a dome (Fig. 2B(4)).

The spicules are cemented together by an organic matrix (Fig. 1D). In this association bundles are formed. In the socket obtained after breaking a branch main bundle rays are seen (Fig. 1E). A cross section of the oscular/apicalbasal axis shows that the bundle rays are organized in a concentric and radiate pattern (Fig. 1F); the section was performed through the middle of the module. The outer cylinder, representing the socket region, is delimited by the dense spicule brushes at the surface and a similar dense spicule arrangement which comes from the cone of the distal module.

\subsection{Spicules: Amphioxea}

Lubomirskia baicalensis is characterized by slightly curved amphioxea that are wholly covered by numerous spines; mature spicules reach sizes of $150-210 \mu \mathrm{m}$ with a thickness of $8-15 \mu \mathrm{m}$ (Masuda et al., 1997); Fig. 3B. Of interest here is the shape polymorphism. Light microscopical studies and also SEM images of the spicules show frequently branching amphioxea (Figs. 3A and C). This abnormal shape is governed by the central axial filament which also branches in a dichotomous manner (Figs. 3A and C); often also bizarre structured spicules are observed. In Fig. 3D a hypersilicified spicule with a polyaxial pattern is shown. On the surface of the spicule in Fig. 3B one small cylinderical ring of silica with a diameter of $5 \mu \mathrm{m}$ can be seen.

\subsection{Orientation of the axial canallfilament}

All sponge spicules have in their central axial canal an axial filament from which the silicification of the spicules 

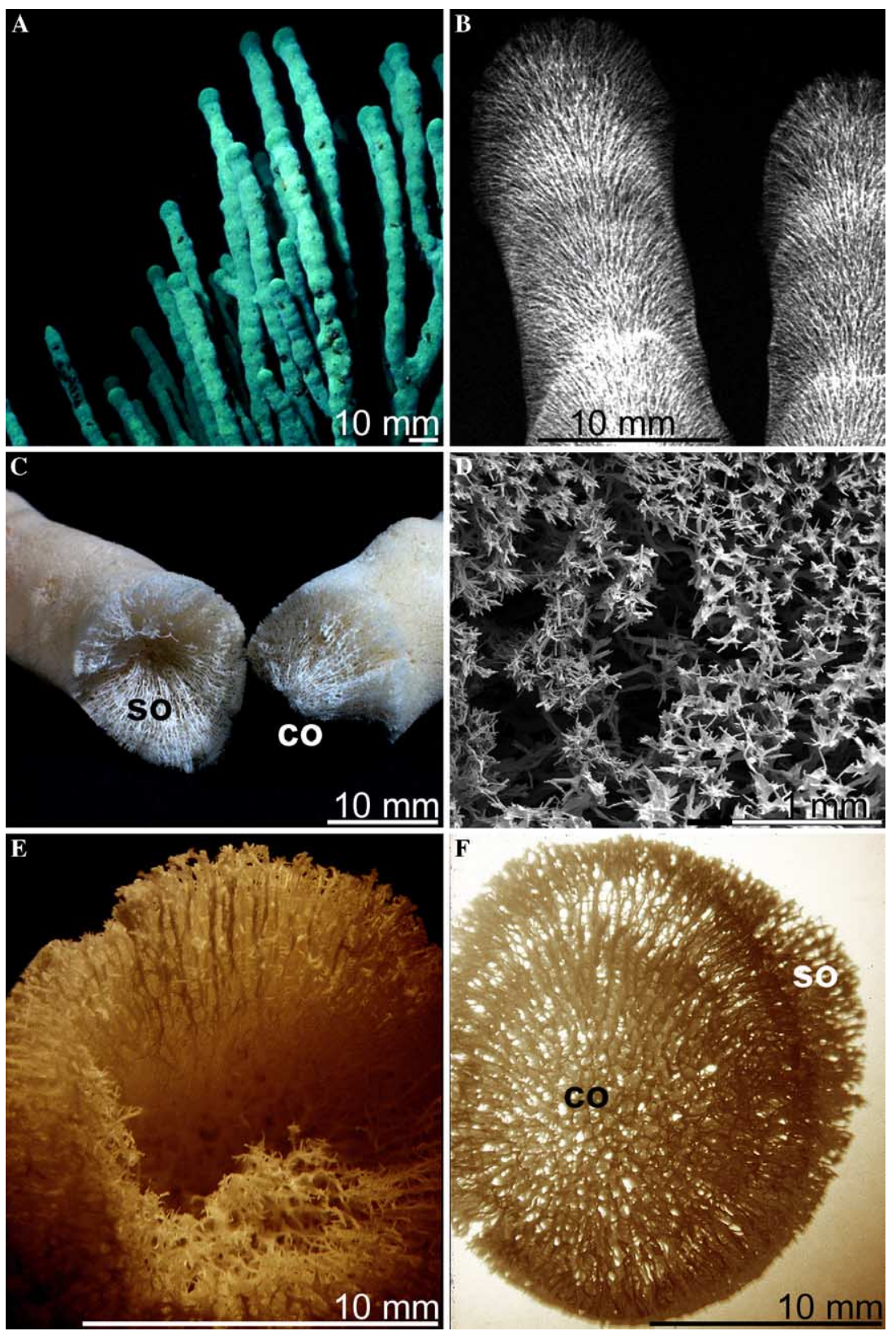

Fig. 1. Serial modular organization of the branches of L. baicalensis. (A) A specimen from the Lake Baikal at a depth of $10 \mathrm{~m}$ in the vicinity of Listvyanka. (B) X-ray analysis of a branch (siliceous skeleton), showing the organized arrangement of the spicules showing the serial modules (modified according to Kaluzhnaya et al., 2005a). (C) Breakage of a branch (siliceous skeleton). The socket (so) is formed at the lower fracture, while the circular cone (co) is from the upper fracture. (D) SEM image of the framework composed of spicules which are cemented together by an organic matrix. (E) The reticulate framework of the bundles (spicules/organic matrix) within a socket, formed after breaking one branch. They are arranged in longitudinal orientation. (F) Cross sections of one branch shows that the rays of bundles are organized in a concentric and radiate pattern. This section shows the outer cylinder (the socket formed by the proximal module; so) and the inner cone (co) which protrudes from the distal module. The size markers are given in millimeter.

begins. As mentioned the surface of the amphioxea in $L$. baicalensis is decorated by many spines. Also, the micrographs in Fig. 4 demonstrate that all spines protruding from the central oxea contain a canal which branches off from the major central canal. The diameters of the canals decrease towards the tips of the main spicule and the spines (Fig. 4B). The cross section in Fig. 4C through a spicule shows two axial canals; the lateral canal fuses with the central canal diagonally to the axis of the spicule.
Axial filaments of spicules were isolated by dissolving the siliceous material of the spicules with hydrofluoric acid. Simultaneously with the liberation of the axial filament, these rods were stained by Coomassie brilliant blue, which had been added to the hydrofluoric acid solution (Fig. 5). Within a time lapse of one min optical micrographs were taken. At the beginning, the surfaces of the partially broken spicules still show spines. With progressing time the silica is dissolved, showing first the perforation of the silica mantel 


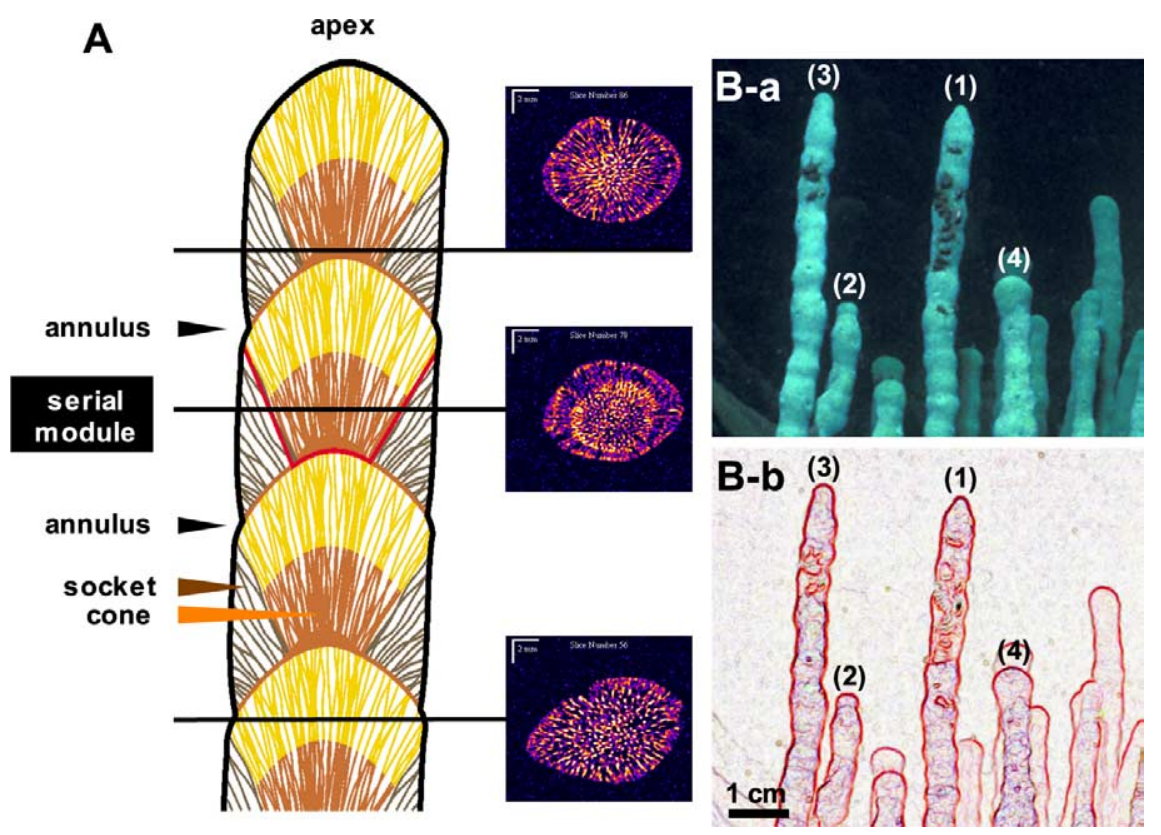

Fig. 2. Schematic representation of serial mode formation. (A) From the surface of an earlier growth stage a small apex is formed (in brown). It is proposed that from this region new spicule bundles originate (fibers in brown - and at the later stage in yellow). With delay, also bundles adjacent to the apex region are formed which form the socket and reach the surface of the skeleton of one serial module (in black). One serial module is delimited by two annuli, one of the transversal lines is formed from the surface of an earlier growth stage and the second from the successive module. At the regions marked the NMR images are given. The three slices show a 3-D MR image (thickness $110 \mu \mathrm{m}$ ) at different positions along the branch; close to the apex (top), in the middle of a module and through an annulus (lower image). The resolution is radial $59 \times 59 \mu \mathrm{m}$. (B) Different forms of tips of branches. In the natural environment the apical end of the branches appears in the following order; (1) as apex on the surface of a newly developing module, (2 and 3) as a cap-like tip and finally (4) as the massive dome-like end of a branch. (B-a) Photo-image of the branches of a sponge specimen, taken during SCUBA diving; (B-b) drawn contours of the surfaces of the branches.
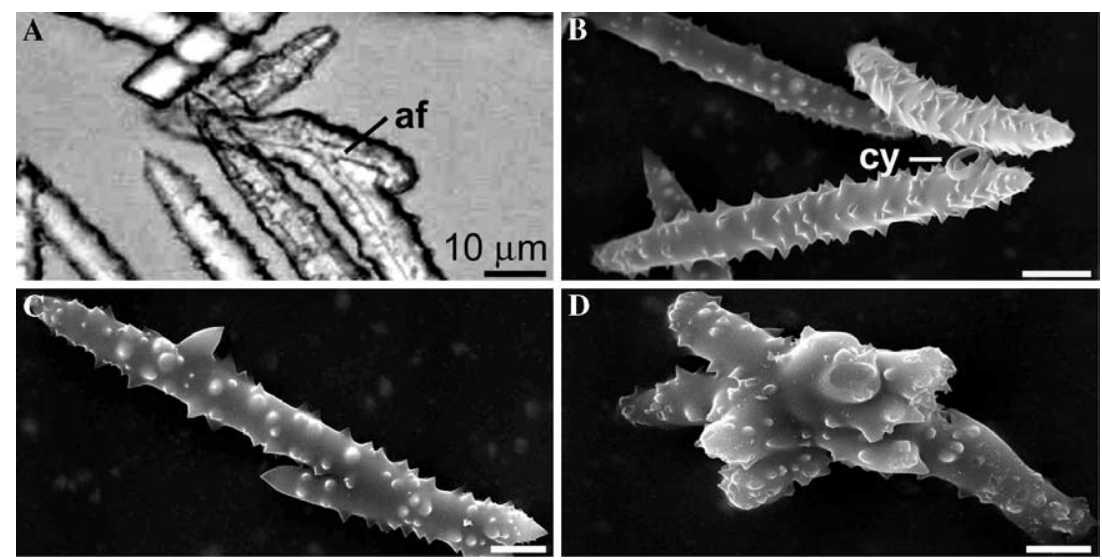

Fig. 3. Amphioxea from L. baicalensis. (A) The light microscopical view shows a dichotomously branched spicule. The axial filament (af) which follows this structure is marked. (B-D) SEM images of amphioxea. (B) Regular shape of a spicule. On its surface one silica cylinders (cy) is shown. (C) Abnormal spicule with one additional major new axis. (D) A hypersilicified spicule with a polyaxial pattern. All scale bars measure $10 \mu \mathrm{m}$.

at the sites where spines had protruded. Finally, the silica is completely dissolved leaving behind only the organic axial filament, which was stained in blue.

\subsection{Ultrastructure of the spicules}

The SEM technique was used to analyze the spicules/ bundles of two macroscopically distinguishable regions within a serial module after breaking a branch; (i) the upper fracture which protrudes as an almost circular cone from the distal module and (ii) the socket which is connected with the proximal module (see, Fig. 2A). The spicules of the socket in the ectosomal skeleton surround the circular cone, and are arranged at the surface like a palisade towards the environment (Figs. 6A and B). At higher magnification transverse sections through the spicules from the socket show that they are formed from massive silica that surrounds the $2-4 \mu \mathrm{m}$ wide axial canal (Figs. $6 \mathrm{C}$ and D). Some spicules show also several concentric layers of silica around the axial filament (Fig. 6C). In contrast, the spicules present 

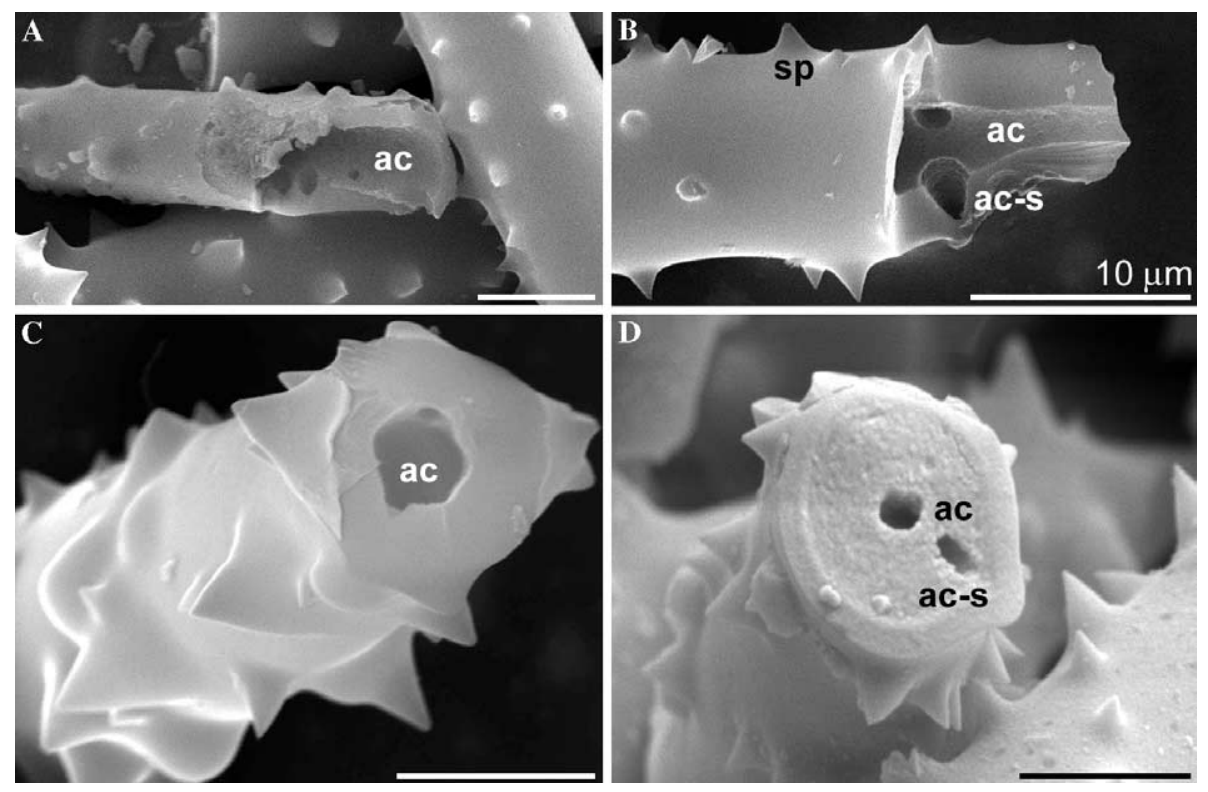

Fig. 4. The orientation of the axial canals in the amphioxea, which are covered by many spines (sp in B); SEM images. (A-C) Broken oxea showing the central axial canal (ac) from which the canals of the spines originate either in diagonal or in rectangular orientation. (D) Transversal fracture of a spicule showing the central axial canal (ac) into which the canal from a spine (ac-s) ends in a diagonally orientation. All size bars measure $10 \mu \mathrm{m}$.

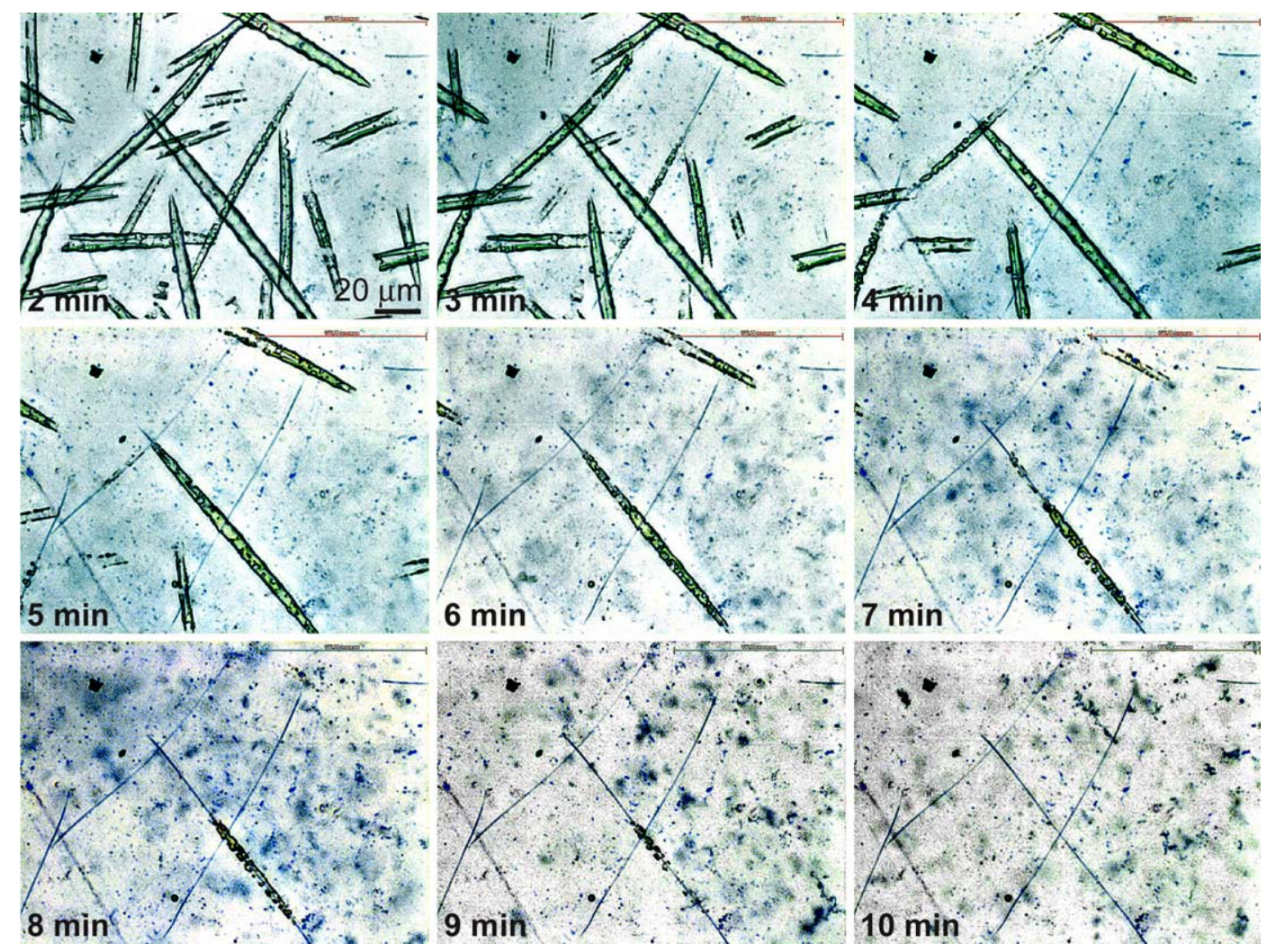

Fig. 5. Dissolution of the polymerized silica of the spicules with hydrofluoric acid in a time lapse period. The optical micrographs were taken progressively every one min; simultaneously with the liberation of the axial filament this fiber became stained blue, using Coomassie brilliant blue. Size bar: $20 \mu \mathrm{m}$.

in the circular cone from a distal module are not compactly formed (Figs. 6E and F). Especially, in an early stage even the inner surface of the axial canal is not smooth, but formed from small silica granules (Fig. 6E). The diameters of those granules vary between 50 and $100 \mathrm{~nm}$.

\subsection{NMR imaging}

This is the first high resolution MRI study on sponge skeleton, which is composed of the inorganic silica and the organic axial filament. The 3-D MR images show the 

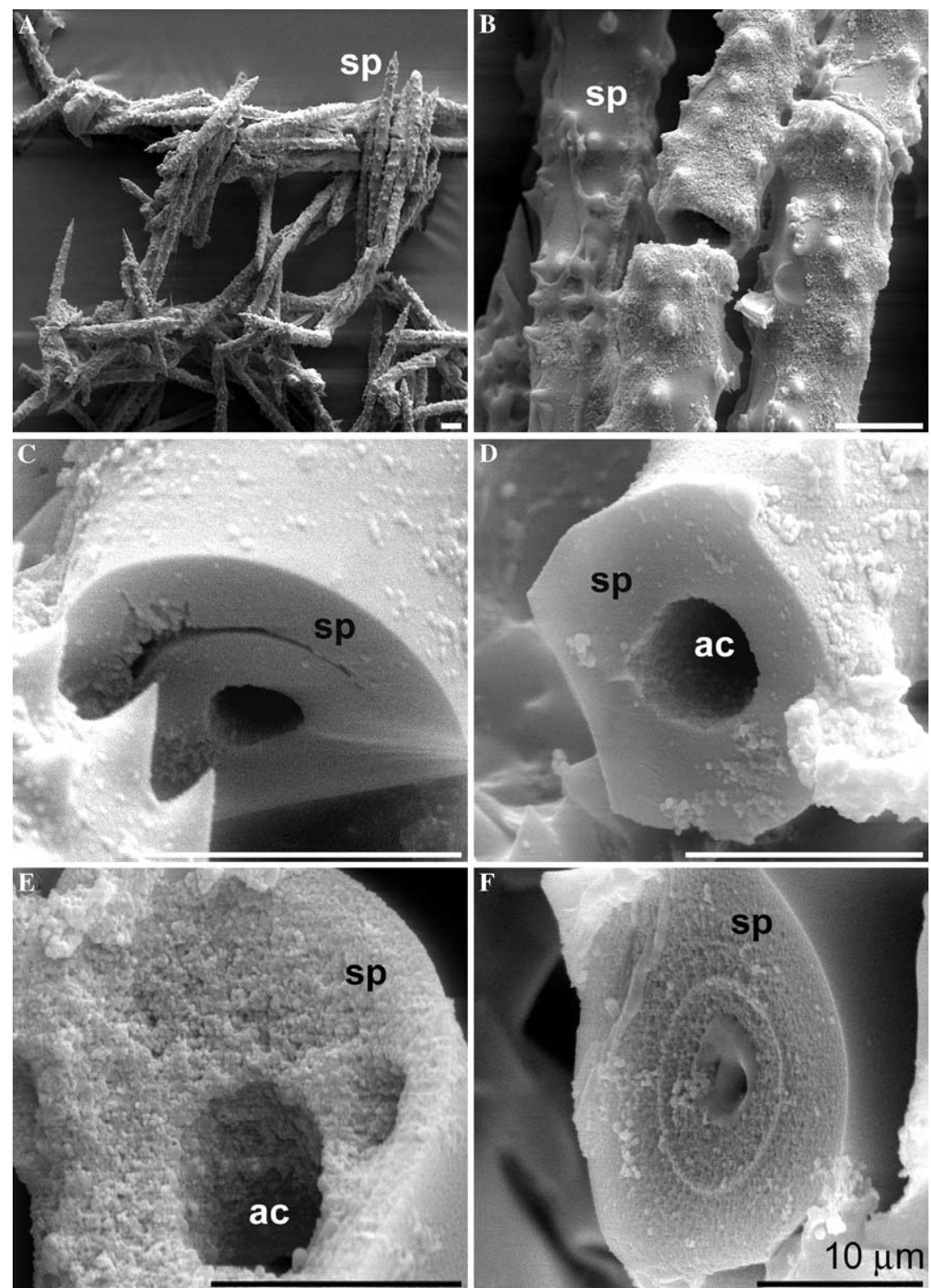

Fig. 6. Ultrastructure of the spicules in the two zones of a module, obtained after braking a branch; the socket attached to the proximal module (A-D) and the circular cone from the distal module (E and F). SEM analysis. (A and B) Palisade-like arrangement of the spicules forming the ectosomal skeleton of the socket which face the environment. (C and D) In transverse sections and at higher magnification the massive silica spicule (sp) is seen which surrounds the axial canal (ac). (E and F) Sections through the spicules from the circular cone unveil that the silica of the spicules (sp) is composed of small granules. In (E) it is obvious that even the inner surface of the silica which surrounds the axial canal is formed from silica spheres.

distributions of hydrogen density contrasted by the amount of hydrogen at the very location together with its (restricted) mobility. The darker the color, the less hydrogen attached to the sponge forming molecules is detectable. This is mainly due to residual water molecules within the sponge skeleton. In the brighter (yellow) parts of the images (Fig. 7a or 1), water (residual water) is relative mobile, giving rise to higher signal intensity, because of the spin-echotechnique used. A lower intensity color (dark red; Fig. 7h or y) reduces the intensity of the spin-echo, and therefore the brightness at this location $(x, y, z)$. As shown in Fig. 7 there are repeating zones along the sponge's longitudinal axis with a very bright filigree outer ring (middle picture in Fig. 7). The annulus region shows a relatively uniform labeling (Fig. 7h or y), while the central bright cone region and the darker socket region (Fig. 7c or p) can be distinguished. The scans were taken from the middle of a serial module (Fig. 7a) via one complete module to a second annulus (Fig. 7y). Therefore, the MRI microimages give valuable insight on a molecular base into the growth modules as described (Müller, 2005).

The distribution of the hydrogen density within a section is also given in parallel to the schematic outline of the spicules construction in a serial modular branch of the sponge (Fig. 2A). At the apex a distinction between the brightly stained cone region and the less bright socket region can be seen (Fig. 2A, top). These differences become even more pronounced in the middle of a module, while at an annulus 

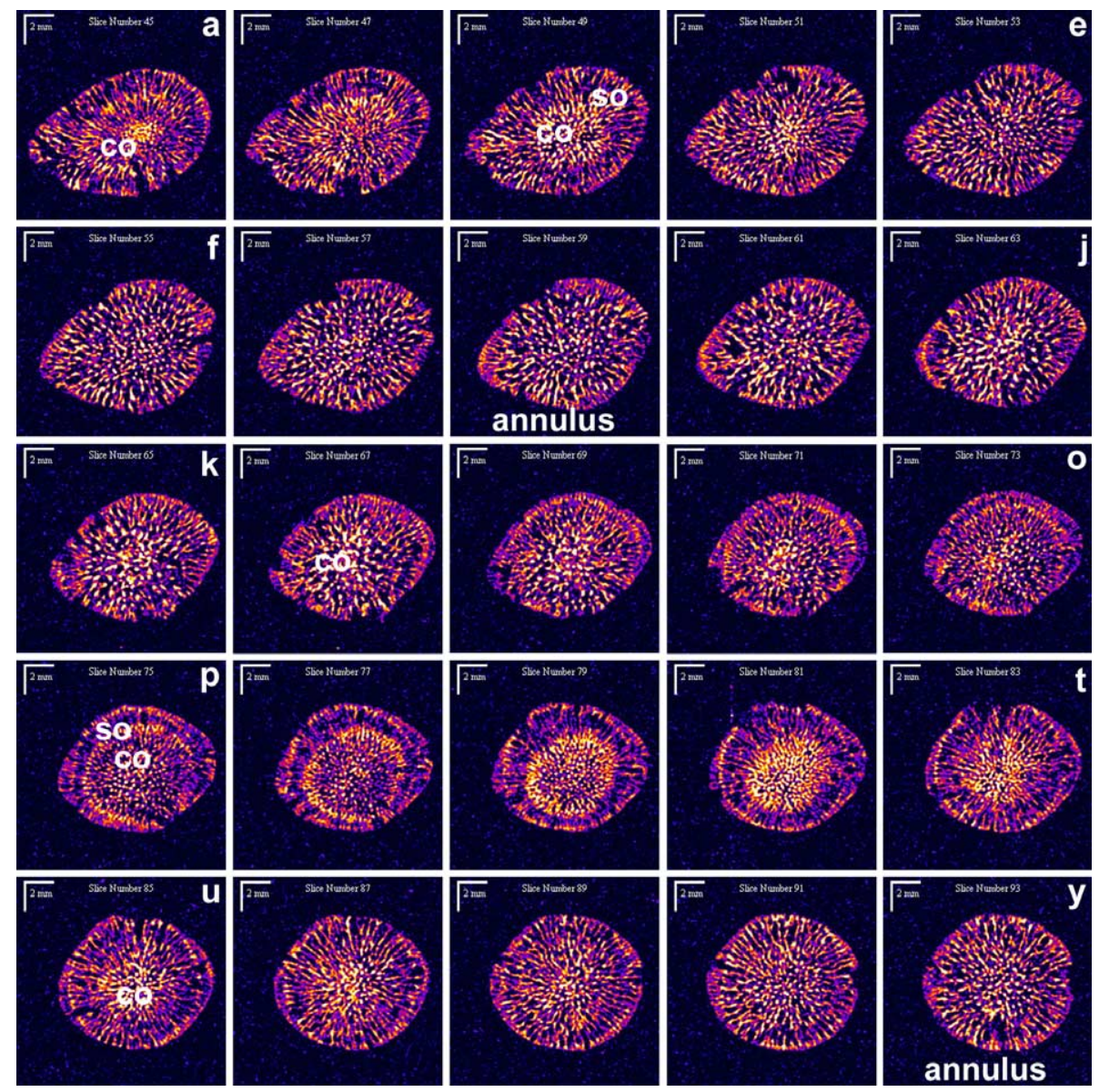

Fig. 7. NMR imaging. A serial analysis of the arborescent sponge L. baicalensis starting from the middle of a module (a), which is characterized by brightly colored spicules, within the longitudinally arranged bundles, originating from the cone (co). With the progression towards the top of the branch the socket (so; darker color) and the cone zone (bright color) can be distinguished (c). Finally the annulus is reached (h) which shows a more homogenous color distribution. Subsequently a further series towards the top of the branch is shown, which ends at a second annulus (y).

the distribution of the hydrogen density is more homogenous (Fig. 2A, below).

\section{Discussion}

Until now only indirect evidence suggested that arborescent demosponges grow according to a serial modular pattern (Müller, 2005). This conclusion was based on the spicule architecture and morphological observations. For the present study, the Lake Baikal sponge L. baicalensis was chosen since this species shows pronounced growth modules along its oscular/apical-basal axis. In earlier studies with Haliclona oculata it was described that the skeleton of this species has a radiate accretive architecture, indicating that during growth newly formed tissue units are apposed onto earlier growth stages (Kaandorp, 1994). In $L$. baicalensis the 1-2.5 cm long modules are delimited by annuli. Breaking of branches reveals that the fractures of the distal modules always contain protruding cones, which fit into the socket of the proximal modules. The end of the cones at the distal modules reaches the surface of the earlier modules. Light microscopical inspections show that the sockets (from the proximal module) are formed from longi- tudinal bundles, composed of spicules, and an organic matrix. The cone protruding from the distal module is likewise composed of spicule/organic matrix bundles which are arranged in a longitudinal direction. In cross sections the two cylinders can be distinguished by the dense spicule organization at the rim of the inner cone.

The dominant form of the spicules $L$. baicalensis are the monaxonic amphioxea, which are covered by many spines. The center of these spicules is formed by an axial canal which contains an axial filament (Kaluzhnaya et al., 2005a) composed of silicatein (Kaluzhnaya et al., 2005b), the enzyme that is involved in the polymerization of silica (Cha et al., 1999; Krasko et al., 2000). An earlier study with the sponge Tethya aurantium (Weaver and Morse, 2003) reported that bifurcation of the axial filament precisely results in an unusual dichotomous morphology of the spicules. In L. baicalensis the degree of unusually formed spicules is high; often biaxonic (with biaxial filaments) or even polyaxonic (polyaxial filaments) spicules are found. Both light microscopical and SEM analyses revealed that bifurcation of spicules is always associated with dichotomous splitting of the axial filament. Important in this context is, that also the conically reducing canal in the spines, that are 
located on the surface of the spicules, is directly connected with the main axial canal. These findings are taken as direct support of the earlier observation in this sponge (Kaluzhnaya et al., 2005a) that silicatein in the filaments is the major enzyme involved in silica deposition. To substantiate the conclusion that also the spines are formed from silicatein/axial filament within the axial canal, experiments with controlled dissolution of spicules have been performed. This series showed that in the course of decomposition of the silica of the spicules by hydrofluoric acid, at first the spines are dissolved, leaving behind holes in the mantle of the main spicule; eventually the axial filaments are completely exposed. It must be mentioned that also in fossilized spicules, e.g., in those from the demosponge Spongilla gutenbergiana from the Tertiary Period (Müller et al., 1982), transverse canals connected with the main axial canal can be observed. Unanswered however, remains the observation that among all axial filaments, seen in the present study at light microscopical magnification, as well as in previous electron microscopical studies (Kaluzhnaya et al., 2005a), none showed any branching; that is, no filament of a spine was found directly attached to a main axial filament and never dichotomously branched main axial filaments were seen. Therefore, we hypothesize that at the nodes of the ramified filaments, either acid-labile covalent linkers or non-covalent linkages must exist. The latter assumption appears to be more realistic, since recently polyamines have been detected in preparations of axial filaments (unpublished).

Detailed SEM analyses of the spicules from the cone region and the socket cylinder showed that the spicules present in the bundles of the socket have $2-4 \mu \mathrm{m}$ wide axial canals which are surrounded by apparently solid silica. From the description of Lithistid demosponge desmas, these solid structures are seen only in mature spicules (Pisera, 2003). In some of these spicules from the socket frequently separate silica layers are seen which may reflect the different growth zones of the spicules (Müller et al., 2005; Sandford, 2003). In contrast, the majority of the spicules from the cones at the distal modules have a different ultrastructure. In the spicules of the cone region, silica has been deposited in granules of sizes between 50 and $100 \mathrm{~nm}$. In non-Lithistid demosponges the granule sizes are between 100 and $160 \mathrm{~nm}$, while in the Lithistid Corallistes sp., the silica granules measure 190-300 nm (Pisera, 2003). It is also interesting to note that the inner surface of the spicule which harbors the axial canal is, in contrast to that of the spicules from the socket, not smooth but covered with the silica spheres. This observation hints at the "immature" stage of these spicules. However, it should be stressed that the silica spheres-containing spicules of the cone region remain in this state also after further growth (apposition of serial modules) of the branch along the axis; it appears that the silica spheres are not transformed to solid layers. A further silica structure should be mentioned here. In Lithistid demosponges silica cylinders, measuring $0.7-2 \mu \mathrm{m}$ in diameter, have been found in close association with newly grow- ing spicules, composed of silica spheres (Pisera, 2003); it is assumed that these spheres represent early stages of spicules. It had been postulated that these cylinders are prestages of spicules. Exactly, such structures have been found in L. baicalensis as well, underscoring the view that besides the spherulous-stage other intermediate stages exist until the final shape of the spicules has been completed.

Recent studies with the enzyme silicatein in an in vitro reaction with tetraethoxysilane demonstrated that silicatein forms under such conditions silica granules, nanospheres, that are have sizes from 70 to $300 \mathrm{~nm}$ (Tahir et al., 2004). In consequence it can be assumed that the same polymerization process for the silica formation occurs in vitro (enzymic reaction) and in vivo (spicule formation). The observation that in the cone region the spicules are composed of silica spheres, while these skeletal elements in the socket bundles are of the solid state strongly suggest that the different ultrastructures of both silica forms is due to their water content. It is well established that during precipitation of silicon in water a transition from the ortho-form of silicic acid via its meta-form to the amorphous, hydrated, and polymerized silicas of the general formula $\mathrm{SiO}_{2} \cdot n \mathrm{H}_{2} \mathrm{O}$ occurs (Perry, 2003; Williams, 1986). This process is paralleled with a loss of water from the condensation products of silicic acid.

In sponge spicules the content of water varies between 6 and $13 \%$, corresponding to an approximate formula of $\left(\mathrm{SiO}_{2}\right)_{2-5} \cdot \mathrm{H}_{2} \mathrm{O}$ (Schwab and Shore, 1971). Therefore, a noninvasive method had to be applied to analyze and quantitate the amount of free mobile water. In an earlier approach to determine the local distribution/amount of water in an intact sponge specimen, the non-invasive technique of nuclear magnetic resonance (NMR) imaging was successfully applied (Bringmann et al., 1999). Now a related NMR technique which is even more sensitive, was chosen, which discriminates structures in the submillimeter range, down to $5 \mu \mathrm{m}$ isotropic voxel resolution for living biological systems, was applied. Here, the spicules, rigid and solidstate objects, have been investigated using the fast threedimensional imaging sequence analysis system, for the first time.

Proton magnetic resonance imaging (MRI) is a noninvasive technique to obtain images for a variety of samples. While it is a standard method to study soft matter with MRI methods, it is much more challenging to obtain proton MR images from essentially stone-like materials [e.g., spicules], as the remaining protons from the organic components of the sponge(s) are strongly immobilized and adequate signal are difficult to resolve, due to the very fast $T_{2}$ decay of the magnetization in solids. $T_{2}$ is a parameter which characterizes the inherent mobility of the molecules, contributing to the NMR-signal. E.g., solid ice has a very short $T_{2}$ in the order of microseconds, bulk water a $T_{2}$ of about $2 \mathrm{~s}$. Furthermore, the single-point imaging (SPI) method can be applied to obtain adequate images of the proton distribution with submillimeter resolution (Emid and Creyghton, 1985; Gravina and Cory, 1994). 
Taken together, the data reported here show that a sponge, characterized by a radiate accretive growth pattern, grows along an axis formed by serial modules (Fig. 2A). One module is delimited by an upper [distal] annulus adjacent to the younger modular unit and a lower [proximal] annulus which forms the border to the module from the earlier growth stage. Based on macroscopic and microscopic observations and on the analysis of the ultrastructure of the skeleton it can be proposed that a new module is formed from the tip of the branch in defined steps. First apices are formed from which the spicules/bundles elongate. These bundles contain spicules, embedded in an organic matrix, which have a rough surface and are composed of $100 \mathrm{~nm}$ large silica granules. NMR analysis revealed that these spicules contain high amounts of 'mobile' water and/or residual biological molecules (including water). Those motions arise form segmental partially rotations/vibrations of these molecules embedded in networks or attached to solid surfaces, preventing their free Brownian motion. In contrast, the spicular bundles which are formed successively from the lateral surface of the ends of the branches contain spicules which comprise a solid silica shell. Together with these bundles the apices broaden, become cap-like and finally reach the shape of a dome. With these structural data in hand, together with recent molecular biological data the body plan patterning in sponges can be explained. Since clusters of homeotic genes are not present in sponges it is assumed that the non-clustered paired-class (Pax-2/5/8)-genes and LIM/homeodomain genes control pattern formation in these animals (Müller et al., 2005). Recently, it could be identified that the organization of spicules is determined by structural proteins (silicatein and mannose-binding lectin) as well as by one regulatory protein (mago nashi) (to be published). In addition, the potential importance of the sponge skeleton, spicules, as light conductors has been recently highlighted (Müller et al., in press).

\section{Acknowledgments}

This work was supported by grants from the Bundesministerium für Bildung und Forschung (Project: Center of Excellence BIOTECmarin), the Deutsche Forschungsgemeinschaft, European Commission, WTZ Germany-Russia (German-Russian cooperation through the BMBF) as well as from the Presidium of the Russian Academy of Science (No. 25.5) and RFBR (No. 03-04-4985).

\section{References}

Arndt, W., 1930. Schwämme-Porifera, Spongien. In: Oppenheimer, C., Pincussen, L. (Eds.), Tabulae Biologicae. W. Junk, Berlin, pp. 39-120.

Bringmann, G., Wolf, K., Lanz, T., Haase, A., Hiort, J., Proksch, P., Müller, W.EG., 1999. Direct demonstration of spatial water distribution in the sponge Suberites domuncula by in vivo NMR imaging. Mar. Ecol. Prog. Ser. 189, 307-310.

Callaghan, P.T., 1991. Principles of Nuclear Magnetic Resonance Microscopy. University Press, Oxford.
Cha, J.N., Shimizu, K., Zhou, Y., Christianssen, S.C., Chmelka, B.F., Stucky, G.D., Morse, D.E., 1999. Silicatein filaments and subunits from a marine sponge direct the polymerization of silica and silicones in vitro. Proc. Natl. Acad. Sci. USA 96, 361-365.

Emid, S., Creyghton, J.H.N., 1985. High resolution NMR imaging in solids. Physica 128B, 81-83.

Grant, R., 1826. Observations and experiments on the structure and functions of the sponge. Philosoph. J. Edinburgh 14, 336-341.

Gravina, S., Cory, D.G., 1994. Sensitivity and resolution of constant-time imaging. J. Magn. Reson. B 104, 53-61.

Hartman, W.D., 1981. Form and distribution of silica in sponges. In: Simpson, T.L., Volcani, B.E. (Eds.), Silicon and Siliceous Structures in Biological Systems. Springer-Verlag, New York.

Jewell, M.E., 1935. An ecological study of the fresh-water sponge of Northern Wisconsin. Ecol. Monogr. 5, 461-504.

Kaandorp, J.A., 1994. Fractal Modelling: Growth and Form in Biology. Springer-Verlag, Berlin.

Kaluzhnaya, O.V., Belikov, S.I., Schröder, H.C., Rothenberger, M., Zapf, S., Kaandorp, J.A., Borejko, A., Müller, I.M., Müller, W.E.G., 2005a. Dynamics of skeletal formation in the Lake Baikal sponge Lubomirskia baicalensis. Part I: Biological and biochemical studies. Naturwissenschaften 92, 128-133.

Kaluzhnaya, O.V., Belikov, S.I., Schröder, H.C., Rothenberger, M., Zapf, S., Kaandorp, J.A., Borejko, A., Müller, I.M., Müller, W.E.G., 2005b. Dynamics of skeletal formation in the Lake Baikal sponge Lubomirskia baicalensis. Part II: Molecular biological studies. Naturwissenschaften 92, 134-138.

Krasko, A., Batel, R., Schröder, H.C., Müller, I.M., Müller, W.E.G., 2000. Expression of silicatein and collagen genes in the marine sponge Suberites domuncula is controlled by silicate and myotrophin. Eur. J. Biochem. 267, 4878-4887.

Kruse, M., Leys, S.P., Müller, I.M., Müller, W.E.G., 1998. Phylogenetic position of the Hexactinellida within the phylum Porifera based on amino acid sequence of the protein kinase $\mathrm{C}$ from Rhabdocalyptus dawsoni. J. Mol. Evol. 46, 721-728.

Maldonado, M., Carmona, M.C., Uriz, M.J., Cruzado, A., 1999. Decline in Mesozoic reef-building sponges explained by silicon limitations. Nature 401, 785-788.

Manz, B., Hillgärtner, M., Zimmermann, H., Zimmermann, D., Volke, F., Zimmermann, U., 2004. Cross-linking properties of alginate gels determined by using advanced NMR imaging and $\mathrm{Cu}^{2+}$ as contrast agent. Eur. Biophys. J. 33, 50-58.

Masuda, Y., Itskovich, V.B., Veinberg, E.V., Efremova, S.M., 1997. Studies on the taxonomy and distribution of freshwater sponges in Lake Baikal. In: Miyazaki, N. (Ed.), Animal Community, Environment, and Phylogeny in Lake Baikal. The University of Tokyo, Tokyo, pp. 21-41.

Müller, W.E.G., 2005. Spatial and temporal expression patterns in animals. in: Meyers, R.A., (Eds.) Encyclopedia of Molecular Cell Biology and Molecular Medicine, vol. 13. Weinheim, Wiley-VCH GmbH, pp. 269-309.

Müller, W.E.G., Zahn, R.K., Maidhof, A., 1982. Spongilla gutenbergiana n.sp., ein Süßwasserschwamm aus dem Mittel-Eozän von Messel. Senckenbergiana lethaea 63, 465-472.

Müller, W.E.G., Krasko, A., Le Pennec, G., Steffen, R., Ammar, M.S.A., Wiens, M., Müller, I.M., Schröder, H.C., 2003. Molecular mechanism of spicule formation in the demosponge Suberites domuncula: silicateincollagen-myotrophin. Prog. Mol. Subcell. Biol. 33, 195-222.

Müller, W.E.G., Wiens, M., Adell, T., Gamulin, V., Schröder, H.C., Müller, I.M., 2004. The Bauplan of the Urmetazoa: the basis of the genetic complexity of Metazoa using the siliceous sponges [Porifera] as living fossils. Int. Rev. Cytol. 235, 53-92.

Müller, W.E.G., Rothenberger, M., Boreiko, A., Tremel, W., Reiber, A., Schröder, H.C., 2005. Formation of siliceous spicules in the marine demosponge Suberites domuncula. Cell Tissue Res. 321, 285-297.

Müller W.E.G., Wendt K., Geppert C., Wiens M., Reiber A., Schröder H.C., in press: Novel photoreception system in sponges? Unique transmission properties of the stalk spicules from the Hexactinellid Hyalonema sieboldi. Biosensors and Bioelectronics, in press (doi:10.1016/ j.bios.2005.04.017). 
Pampel, A., Volke, F., 2004. Studying lyotropic liquid crystalline phases using high resolution Mas NMR spectroscopy. In: Haberlandt, R., Michel, D., Pöppl, A., Stannarius, R. (Eds.), Molecules in Interaction with Surfaces and Interfaces-Lecture Notes in Physics, vol. 634. Springer-Verlag, Heidelberg, pp. 439-464.

Perry, C.C., 2003. Silicification: the process by which organisms capture and mineralize silica. Rev. Mineral. Geochem. 54, 291-327.

Pisera, A., 2003. Some aspects of silica deposition in Lithistid demosponge desmas. Microsc. Res. Techniq. 62, 312-326.

Sandford, F., 2003. Physical and chemical analysis of the siliceous skeletons in six sponges of two groups (Demospongiae and Hexactinellida). Microsc. Res. Techniq. 62, 336-355.

Schröder, H.C., Perović-Ottstadt, S., Wiens, M., Batel, R., Müller, I.M., Müller, W.E.G., 2004a. Differentiation capacity of the epithelial cells in the sponge Suberites domuncula. Cell Tissue Res. 316, 271-280.

Schröder, H.C., Perović-Ottstadt, S., Rothenberger, M., Wiens, M., Schwertner, H., Batel, R., Korzhev, M., Müller, I.M., Müller, W.E.G., 2004b. Silica transport in the demosponge Suberites domuncula: fluorescence emission analysis using the PDMPO probe and cloning of a potential transporter. Biochem. J. 381, 665-673.
Schultze, M.J.S., 1860. Die Hyalonemen. Ein Beitrag zur Naturgeschichte der Spongien. A. Marcus Verlag, Bonn. pp. 1-46.

Schwab, D.W., Shore, R.E., 1971. Fine structure and composition of a siliceous sponge spicule. Biol. Bull. 140, 125-136.

Shimizu, K., Cha, J., Stucky, G.D., Morse, D.E., 1998. Silicatein alpha: cathepsin L-like protein in sponge biosilica. Proc. Natl. Acad. Sci. USA 95, 6234-6238.

Simpson, T.L., 1984. The Cell Biology of Sponges. Springer-Verlag, New York.

Tahir, M.N., Théato, P., Müller, W.E.G., Schröder, H.C., Janshoff, A., Zhang, J., Huth, J., Tremel, W., 2004. Monitoring the formation of biosilica catalysed by histidin-tagged silicatein. Chem. Commun. 24, 2848-2849.

Weaver, J.C., Morse, D.E., 2003. Molecular biology of demosponge axial filaments and their roles in biosilicification. Microsc. Res. Techniq. 62, 356-367.

Weissenfels, N., 1989. Biologie und Mikroskopische Anatomie der Süßwasserschwämme Spongillidae. Gustav Fischer Verlag, Stuttgart.

Williams, R.J.P., 1986. Introduction to silicon chemistry and biochemistry. In: Evered, D., O’Connor, M. (Eds.), Silicon Biochemistry. John Wiley, Chichester, pp. 24-34. 